\title{
Torpor in Dark Times: Patterns of Heterothermy are Associated with the Lunar Cycle in a Nocturnal Bird
}

\author{
${ }^{*}$ Ben Smit ${ }^{1}$, Justin G. Boyles ${ }^{1}$, R. Mark Brigham ${ }^{2}$, and Andrew E. McKechnie ${ }^{1}$ \\ ${ }^{1}$ DST/NRF Centre of Excellence at the Percy FitzPatrick Institute, Department of Zoology and \\ Entomology, University of Pretoria, Pretoria 0002, South Africa; ${ }^{2}$ Department of Biology, University of \\ Regina, Regina, SK S4S 0A2, Canada \\ *Corresponding author: smitbe@gmail.com
}

Running Head: Heterothermy and the lunar cycle

Number of Pages: 24 (12 pages of text)

Number of Tables: 0

Number of Figures: 5

Abstract Many studies have shown that endotherms become more heterothermic when the costs of thermoregulation are high and/or when limited energy availability constrains thermoregulatory capacity. However, the roles of many ecological variables, including constraints on foraging opportunities and/or success, remain largely unknown. To test the prediction that thermoregulatory patterns should be related to foraging opportunities in a heterothermic endotherm we examined the relationship between the lunar cycle and heterothermy in Freckled Nightjars (Caprimulgus tristigma), which are visually orienting, nocturnal insectivores that are dependent on ambient light to forage. This model system provides an opportunity to assess whether variation in foraging 
opportunities influences the expression of heterothermy. The nightjars were active and foraged for insects when moonlight was available, but became inactive and heterothermic in the absence of moonlight. Lunar illumination was a much stronger predictor of the magnitude of heterothermic response than was air temperature $\left(\mathrm{T}_{\mathrm{a}}\right)$. Our data suggest that heterothermy was strongly related to variation in foraging opportunities associated with the lunar cycle, even though food abundance appeared to remain relatively high throughout the study period. Patterns of thermoregulation in this population of Freckled Nightjars provide novel insights into the environmental and ecological determinants of heterothermy, with the lunar cycle, and not $\mathrm{T}_{\mathrm{a}}$, being the strongest predictor of torpor use.

Key words Caprimulgidae, foraging, Freckled Nightjars, homeothermy, moon, torpor

Increasing awareness of the importance of heterothermy in the evolution of endothermy (Grigg et al. 2004) has led to a proliferation of studies on the ecological significance of variation in body temperature $\left(\mathrm{T}_{\mathrm{b}}\right)$. It is becoming increasingly clear that some form of heterothermy may be universal in endotherms (Angilletta et al. 2010; Arnold et al. 2004), and many researchers have begun searching for ecological and physiological variables that explain when and why endotherms should allow their $\mathrm{T}_{\mathrm{b}}$ to vary. Until recently, the majority of studies have focused on one of two factors affecting heterothermy in endotherms: air temperature $\left(\mathrm{T}_{\mathrm{a}}\right)$ and food availability (e.g. Bozinovic et al. 2007; Mzilikazi and Lovegrove 2004). However, recent studies, especially on sub-tropical species, have shown that $\mathrm{T}_{\mathrm{a}}$, food availability, and energy stores are not necessarily the only predictors of heterothermy. In fact, a multitude of other ecological factors (e.g. 
predation risk or variable environmental temperatures) might also be important determinants of heterothermy in endotherms (Bieber and Ruf 2009; Mzilikazi et al. 2002; Stawski and Geiser 2010; Warnecke et al. 2008). Efforts have been made to generalize all factors affecting the expression of $\mathrm{T}_{\mathrm{b}}$, whether well studied or not, into an adaptive framework (Angilletta et al. 2010; Humphries et al. 2003). Generally speaking these authors posit that endotherms should become more heterothermic when any factor either increases the cost of thermoregulation (e.g. cold weather) or constrains an organism's metabolic heat production (e.g. energy shortages).

Energy availability related to either foraging success or foraging opportunities has seldom been assessed in the context of the expression of heterothermy. A notable exception is a study by Schubert et al. (2009), who showed that torpor incidence was higher when female lab mice were subjected to experimentally elevated foraging costs. However, data of this kind from free-living animals are scarce. Pravosudov and Lucas (2000) modeled the use of nocturnal heterothermy in a small diurnal bird under conditions of varying foraging success. Their model predicts that nocturnal heterothermy should increase as diurnal foraging success decreases. Logically, this prediction should be easily generalized to account for species with different foraging behaviours and activity cycles. For example, birds and mammals that rely on visual cues for detecting prey at night are known to vary their activity patterns with the lunar cycle, which in turn affect foraging opportunities or foraging success (Brigham and Barclay 1992; Brigham et al. 1999; Horning and Trillmich 1999; Jetz et al. 2003; Woods and Brigham 2008). By extension, it seems likely that nocturnal insectivorous birds that use heterothermy will use moonlight as a proximate cue to evaluate foraging opportunities, and adjust their $T_{b}$ 
patterns in accordance with the lunar cycle. Whereas food availability is one determinant of foraging success, other factors may be equally or more important. For example, foraging opportunities may be reduced by adverse weather conditions or when predation risk necessitates increased vigilance.

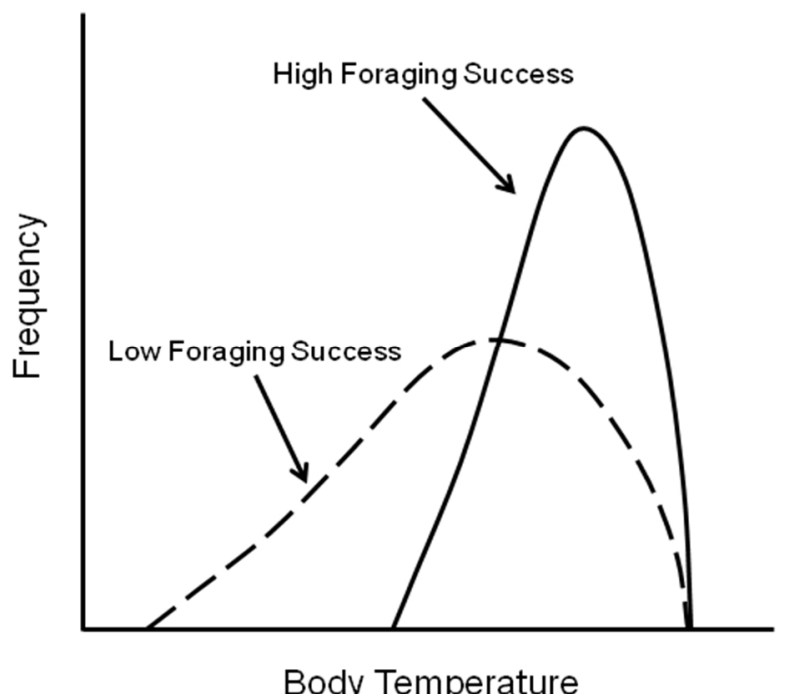

Fig. 1: An adaptive framework of endothermic thermoregulation predicts the distribution of body temperatures $\left(T_{b}\right)$ should vary with foraging success or opportunities. When successful foraging is possible, endotherms should maintain a narrow range of $\mathrm{T}_{b} \mathrm{~S}$ around the optimal temperature for performance (sensu Huey and Slatkin 1976). When foraging opportunities are rare, endotherms should allow $T_{b}$ to vary widely (modified from Angilletta et al. 2010)

Here we test the prediction that thermoregulatory patterns should be related to foraging opportunities in a heterothermic endotherm (Fig. 1). We report a novel pattern of heterothermy $-\mathrm{T}_{\text {skin }}$ strongly related to the lunar cycle - in a population of Freckled Nightjars (Caprimulgus tristigma lentiginosus) from a semi-arid region where primary productivity and insect abundance peak during winter. Caprimulgids are excellent models 
for answering questions about heterothermy and foraging opportunities, since they are nocturnal, visual predators whose nocturnal foraging windows are limited to moonlight and twilight (Jetz et al. 2003).

\section{MATERIALS AND METHODS}

Study site and Species. The Freckled Nightjar is a nocturnal aerial insectivore which occurs in rocky habitats over much of sub-Saharan Africa (Spottiswoode and Jackson 2005). Freckled Nightjars can enter torpor (McKechnie et al. 2007) and activity levels are correlated with ambient light levels and temperature (Ashdown and McKechnie 2008). We investigated thermoregulatory patterns of Freckled Nightjars during June and July (austral winter) 2009 and 2010 in an arid northern valley of the Kamiesberg Mountains $\left(30^{\circ} 02^{\prime} \mathrm{S}, 017^{\circ} 59^{\prime}, 600-1000 \mathrm{~m}\right.$ a.s.l.), in the Namaqualand region of western South Africa. The Kamiesberg range is within the succulent Karoo desert biome (sensu Mucina et al. 2006) characterized by a rich diversity of winter-flowering plants and peak productivity in winter (annual rainfall at the study site is $170-220 \mathrm{~mm}$ : P. Benadie pers. comm.). During winter (May to August) cold fronts periodically move over the region, resulting in light rain and dense fog, whereas summers are dry and hot.

Data Collection. We recorded air temperature $\left(\mathrm{T}_{\mathrm{a}}\right)$ using iButtons (DS1922L, $0.0625^{\circ} \mathrm{C}$ resolution, Dallas Semiconductor, Dallas, USA) suspended in the shade $\sim 1 \mathrm{~m}$ above the ground near regularly used roost sites of tagged nightjars ( $<2 \mathrm{~km}$ apart, $660-750 \mathrm{~m}$ a.s.l) and a portable weather station (Vantage Pro2 ${ }^{\mathrm{TM}}$, Davis Instruments, Hayward, CA), all of which were calibrated against an NIST-traceable mercury thermometer before the study. 
We obtained telemetric measurements of skin temperature $\left(\mathrm{T}_{\text {skin }}\right)$ for Freckled Nightjars, following the methods of McKechnie et al. (2007). Skin temperature is widely used to asses thermoregulatory patterns of birds, and although $\mathrm{T}_{\text {skin }}$ is not exactly equal to $T_{b}$, it is a robust proxy of nocturnal $T_{b}$ in birds (Brigham et al. 2000; McKechnie et al. 2007; Smit and McKechnie 2010). The temperature-sensitive radio-transmitters (2.5g, model PD-2T, Holohil Systems, Carp, Ontario, Canada) were pre-calibrated in a temperature-controlled water bath at temperatures between $5^{\circ}$ and $45^{\circ} \mathrm{C}$, using an NISTtraceable mercury thermometer. We captured and attached transmitters to eight adult birds, but two moved to inaccessible valleys shortly after release. We thus monitored two females (69 and $68 \mathrm{~g}$ ) and one male (62 g) in 2009, and three males (89, 84 and $66 \mathrm{~g}$ ) in 2010. We obtained 9, 11, 12, 20, 21 and 37 nights, respectively, of data for the six individuals for a total of 110 bird-nights. For each individual we calculated mean transmitter pulse intervals from three consecutive manual timings of 10 pulse intervals using a stopwatch, at least once each hour throughout the night. We noted whether an individual was moving or stationary based on modulation of pulses (Brigham et al. 1999), although we could not determine activity levels each time we obtained $\mathrm{T}_{\text {skin }}$ measurements as the birds were often too far away to assess the modulation of pulses. When an individual was stationary at its roost site or whenever we received a clear signal, we used digital voice recorders (Jukem@n, JX-MP104BLK, jWIN Electronics Corp, Port Washington, USA and Sony® Walkman, NWZ-B142F, Sony Corporation, China) to record transmitter pulses of the focal bird for up to $10 \mathrm{hrs}$. Pulse-rates of these recordings were subsequently determined using a freeware digital audio editor (Audacity 1.2.6; www.audacity.sourceforge.net/) after verifying that differences in the recorders did not 
affect pulse rates. We found that pulse intervals were on average $0.12 \mathrm{~s}$ faster (maximum $\mathrm{T}_{\text {skin }}$ error $=0.3^{\circ} \mathrm{C}$ ) when timed with a stopwatch than when calculated from the digitally timed pulse-intervals, irrespective of whether slow or fast pulses were timed. Multiple attempts to accurately quantify nocturnal aerial insect abundance were unsuccessful, but we noted an abundance of flying moths on all nights during the study (even on cold nights when minimum $\mathrm{T}_{\mathrm{a}}<5{ }^{\circ} \mathrm{C}$ ). We obtained lunar cycle data from Time and Date AS (www.timeanddate.com/worldclock/moonrise.html). We used percentage lunar illumination data for simplicity in analyses because this metric is highly correlated with the amount of time the moon is above the horizon on a night (and other measurements of the moon phase), although cloud cover might have occasionally affected the intensity of lunar illumination.

Data Analysis. We assumed the upper modal $\mathrm{T}_{\text {skin }}\left(\mathrm{T}_{\text {skin-mod }}\right)$ to be indicative of optimal $\mathrm{T}_{\text {skin }}$ (see Fig. 1.) for each individual (Boyles et al. 2011; McKechnie et al. 2007) and then estimated the extent of heterothermy for each bird on each night using a simple metric called the Heterothermy Index (HI):

$$
H I=\sqrt{\frac{\sum\left(T_{s k i n-\bmod }-T_{s k i n-i}\right)^{2}}{n-1}}
$$

where $\mathrm{T}_{\text {skin-mod }}$ is the modal $\mathrm{T}_{\text {skin, }}, \mathrm{T}_{\text {skin-i }}$ is the $\mathrm{T}_{\text {skin }}$ measurement at time $i$ and $n$ is the number of times $\mathrm{T}_{\mathrm{b}}$ is sampled. The $\mathrm{HI}$ gives an estimate of variation in $\mathrm{T}_{\text {skin }}$ around the modal $\mathrm{T}_{\text {skin }}$ and does not rely on an arbitrary cut-off for defining torpor bouts as has been used in most studies (Boyles et al. 2011). We calculated HI values for the period between 19h00 and 7h00, which was when sampling was most intensive, and ensured that we did not include morning torpor bouts into calculations of nocturnal heterothermy. On moonlit 
nights the birds were often very active and difficult to monitor, resulting in gaps in the data set, and to prevent any bias towards $\mathrm{T}_{\text {skin }}$ measurements from stationary heterothermic birds we therefore only included bird-nights with at least $15 \mathrm{~T}_{\text {skin }}$ recordings spread every 30-60 min across the entire sampling period. We used the mean nightly $\mathrm{T}_{\mathrm{a}}$ between $19 \mathrm{~h} 00$ and $7 \mathrm{~h} 00$ in analyses because the HI metric takes into account data from the entire night.

We first analyzed relationships between environmental variables ( $\%$ lunar illumination and $\mathrm{T}_{\mathrm{a}}$ ) and $\mathrm{HI}$ for each bird separately using both simple linear and multiple regression analyses. We included the linear regressions to enable comparisons with previous studies that did not consider the effects of moon on the expression of heterothermy. We then evaluated possible differences between years in the relationships between the environmental variables and HI using separate, repeated-measures analyses of variance models. For several logistical reasons, including gaps in the data, a single, unbiased model including both $\mathrm{T}_{\mathrm{a}}$ and $\%$ lunar illumination for all six individuals was not possible using raw data. Thus, we used the partial correlation coefficients obtained from the multiple regression analyses to enable inclusion of the effect of $\mathrm{T}_{\mathrm{a}}$ on the relationship between \% lunar illumination and $\mathrm{HI}$ and vice versa. This means the analysis is only meaningful for determining if the slopes of the relationships between the environmental variables and HI varied between years. We calculated the regression solution using the PROC MIXED function in SAS to account for repeated observations within individuals (Version 9.2, SAS Inc., Cary, NC, USA) and assumed a type-I error rate of 0.05. To model correlation within experimental units across time and between experimental units, we first determined the appropriate covariance structure for each dataset based on Akaike 
Information Criterion adjusted for small sizes $\left(\mathrm{AIC}_{\mathrm{c}}\right)$. We considered year as a fixed effect and the environmental variable of interest as a random effect.

We tested for differences in mean $\mathrm{T}_{\text {skin }}$ before and after moonset and moonrise (i.e. variation in illumination during a single night), using a paired t-test. $M$ ean $T_{\text {skin }}$ was calculated from at least three consecutive readings during the two hours before and after moonrise or moonset.

\section{RESULTS}

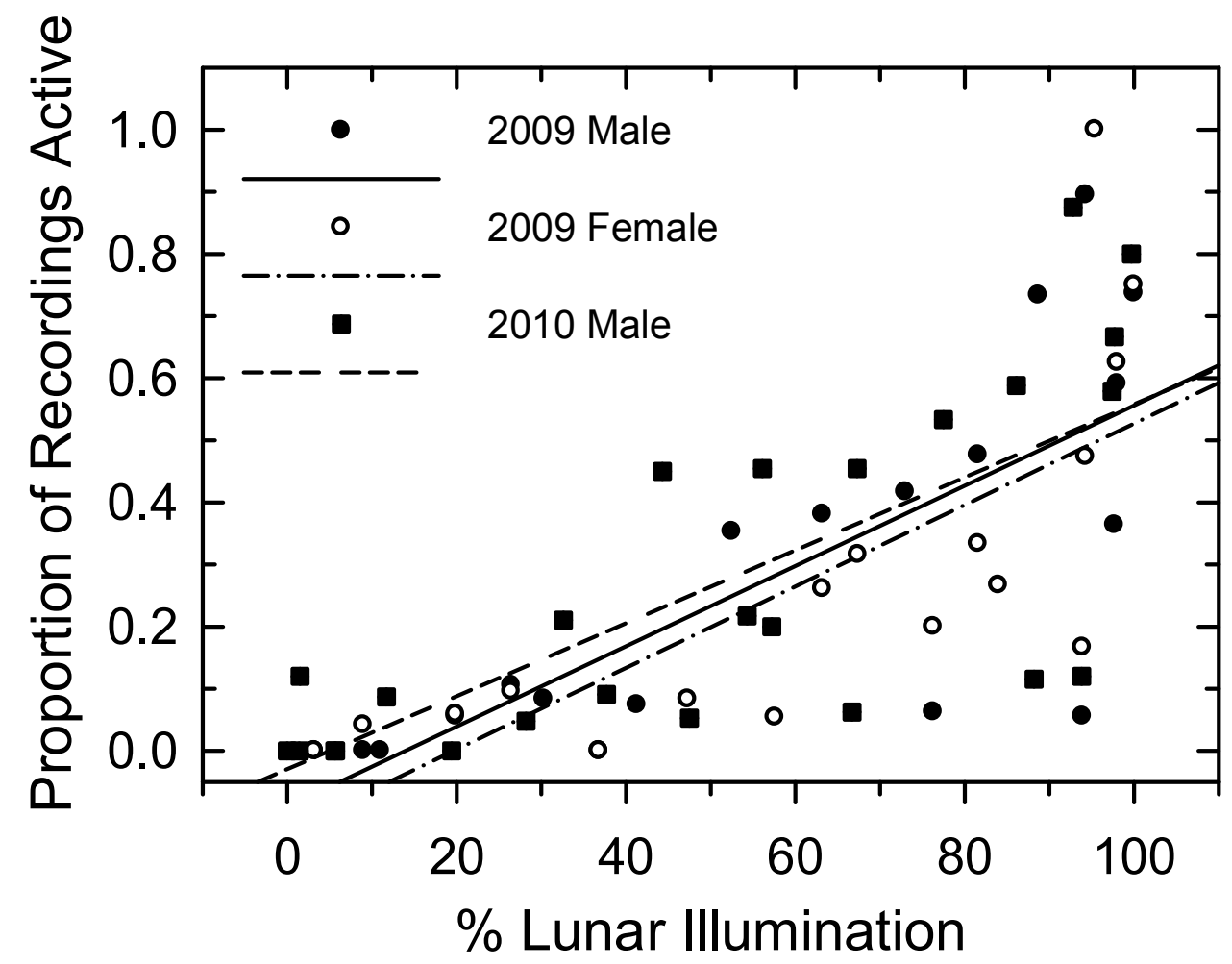

Fig. 2: The proportion of recordings during which the bird was active, as judged by modulation in the signal for two birds during winter 2009 and one bird during winter 2010. The trend lines represent linear regressions of proportion of activity and lunar illumination for the three individual birds $\left(\mathrm{R}^{2}=0.558,0.565\right.$ and 0.574 , respectively, all $\left.p<0.001\right)$. 
The grand mean of mean night-time $\mathrm{T}_{\mathrm{a}}$ was $11.5 \pm 2.7^{\circ} \mathrm{C}$ (mean night-time $\mathrm{T}_{\mathrm{a}}$ on coldest night $\left.=5.6^{\circ} \mathrm{C}\right)$ and $9.2 \pm 4.1^{\circ} \mathrm{C}\left(\mathrm{T}_{\mathrm{a}}=1.1^{\circ} \mathrm{C}\right)$ during the study periods of 2009 and 2010, respectively. The winter of 2009 was substantially wetter than 2010 with approximately $120 \mathrm{~mm}$ of rain falling during the 6 week study period (90 mm falling during 22-24 June) compared to only $50 \mathrm{~mm}$ of rain during June and July 2010 .

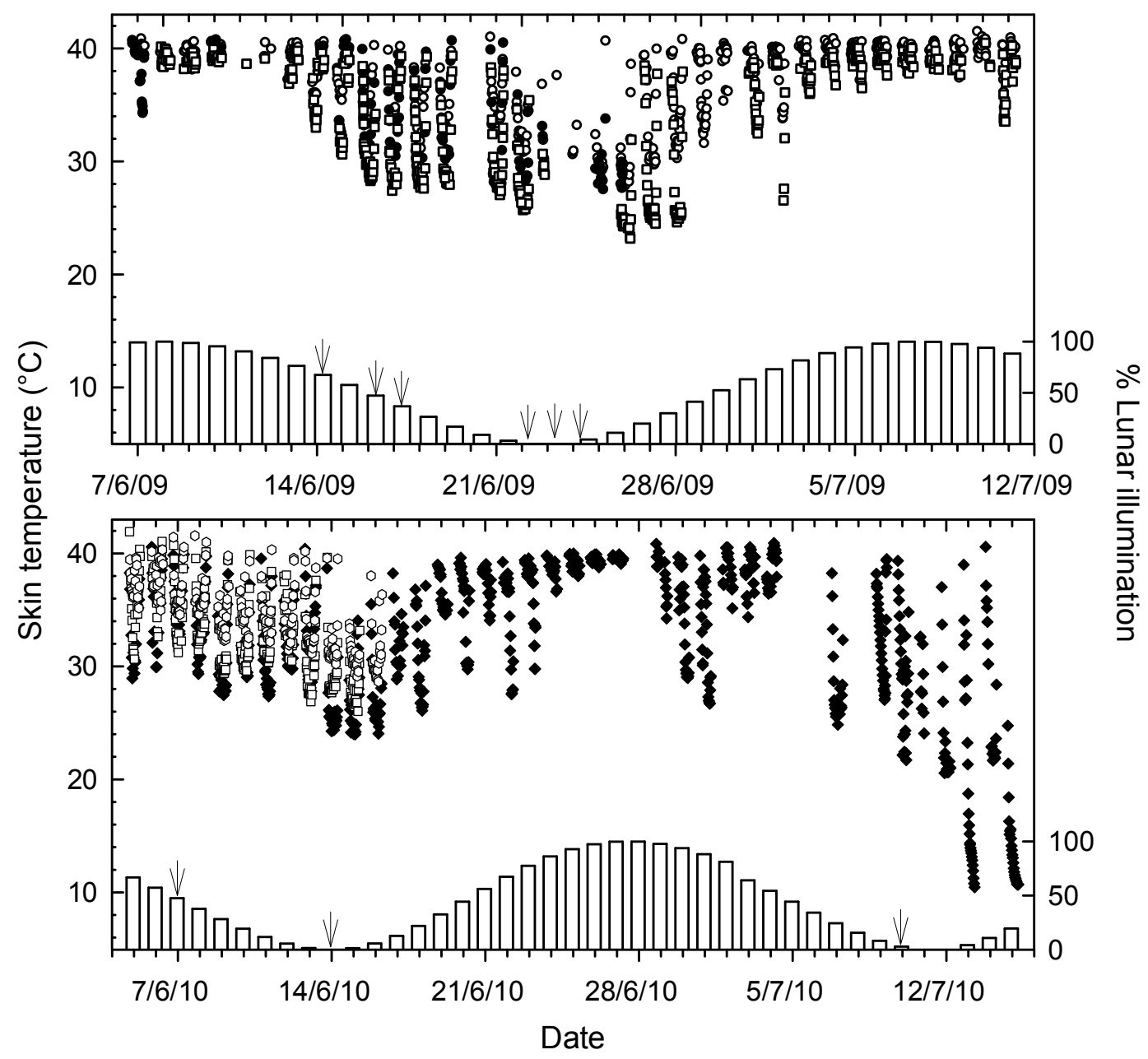

Fig. 3: Skin temperatures $\left(T_{\text {skin }}\right.$ ) recorded in Freckled Nightjars (symbols) during 2009 (top panel; $\mathrm{n}=3$ ) and 2010 (bottom panel; $\mathrm{n}=3$ ). Skin temperature was significantly related to $\%$ lunar illumination (clear bars), with the lowest and highest minimum $\mathrm{T}_{\text {skin }}$ recorded around new moon and full moon, respectively. The arrows indicate nights on which precipitation occurred. 
Mean $\mathrm{T}_{\text {skin-mod }}$ for the six birds during periods of normothermy was $39.2^{\circ} \pm 0.4^{\circ} \mathrm{C}$. We obtained sufficient activity data to analyze the relationship between lunar illumination and activity for three individuals, two in 2009 and one in 2010. Activity levels increased significantly (all $p<0.001$ ) with lunar illumination in all three of these birds (Fig. 2). Skin temperature varied widely and predictably, with the greatest variation occurring around new moon in both years (Fig. 3). Skin temperature during heterothermy was typically regulated between $20^{\circ}$ and $30^{\circ} \mathrm{C}$ by all six individuals (Fig. 3). However, one bird reduced $\mathrm{T}_{\text {skin }}$ to 10.5 and $10.7^{\circ} \mathrm{C}$ on two consecutive nights after the new moon of 11 July 2010 (Fig. 3). On the second night that a low $\mathrm{T}_{\text {skin }}$ recording was obtained, we located the individual at its roost-site in a rock crevice to confirm that the readings were not the result of a loose transmitter; the individual was cold to touch and extremely lethargic, but eventually responded to our handling by raising its wings, opening its mouth and growling softly. Thus, we are satisfied that the low $\mathrm{T}_{\text {skin }}$ values are accurate.

Linear regressions between \% lunar illumination and HI were highly significant for all six birds (all $p<0.001$ ) and the relationship between $\mathrm{T}_{\mathrm{a}}$ and HI was significant for five of the six birds $(p<0.05)$. However, when $\%$ lunar illumination and $\mathrm{T}_{\mathrm{a}}$ were included in a single multiple regression model, the relative strength of the relationships changed (Fig. 4). In 2009, the relationship between \% lunar illumination and HI remained highly significant for all three birds (all $p<0.005)$ while the relationship between $\mathrm{T}_{\mathrm{a}}$ and HI was non-significant for all three $(p=0.057,0.12$, and 0.38$)$. In 2010, the relationship between \% lunar illumination and $\mathrm{HI}$ remained significant for all three birds after accounting for $\mathrm{T}_{\mathrm{a}}$ in the multiple regressions (all $p<0.03$ ). Unlike 2009, the relationship 
Ambient Temperature $\left({ }^{\circ} \mathrm{C}\right)$
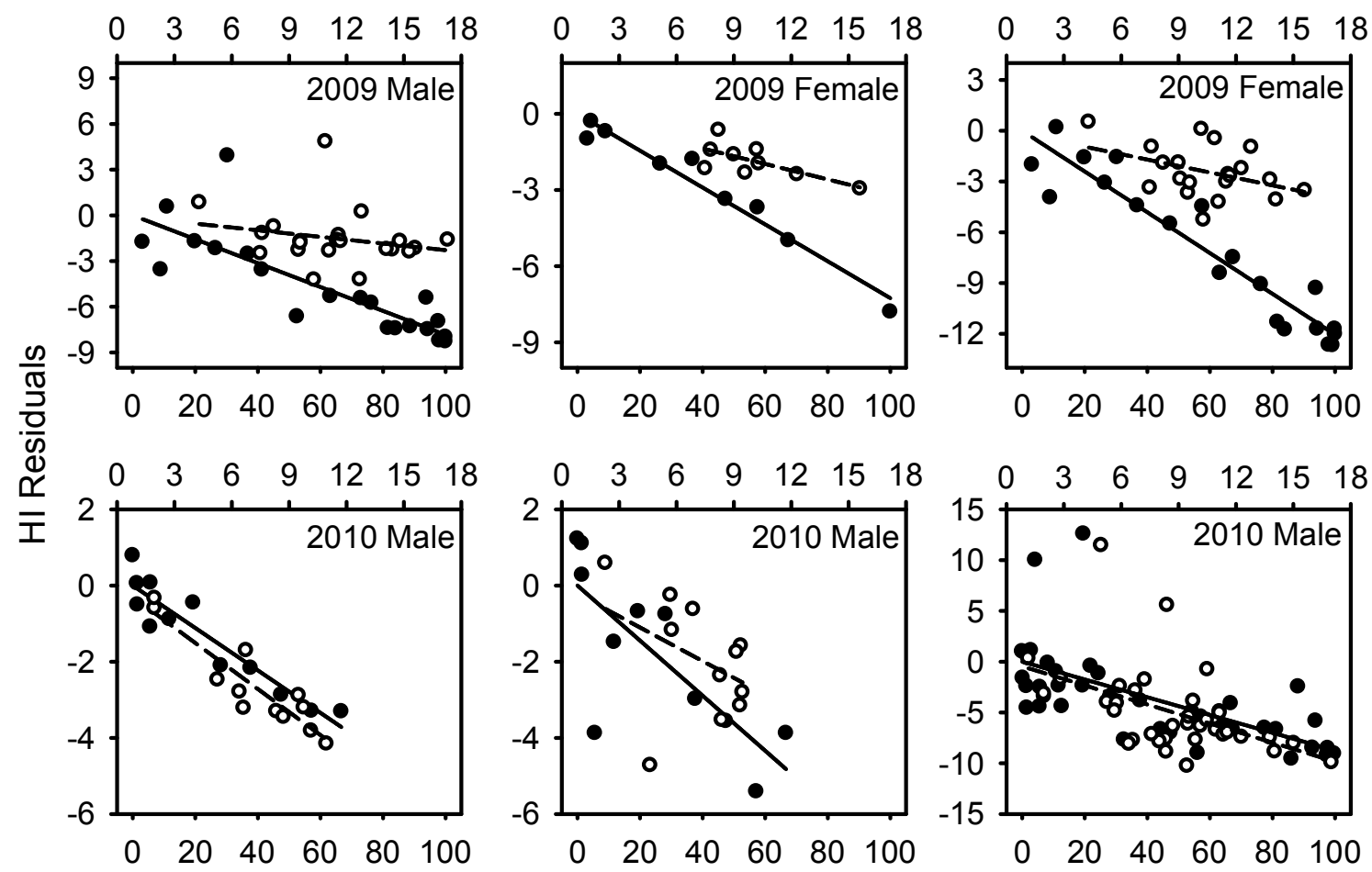

Lunar Illumination (\%)

Fig. 4: Partial correlations for the relationships between environmental variables (\% lunar illumination and air temperature $\left[\mathrm{T}_{\mathrm{a}}\right]$ ) and Heterothermy Index (Boyles et al. 2011) values for six Freckled Nightjars. Black and white circles represent \% lunar illumination and air temperature, respectively. The top row represents data from birds recorded in 2009 while the bottom row represents birds in 2010. The relative effect of \% lunar illumination on heterothermy was similar between the two years, but $\mathrm{T}_{\mathrm{a}}$ was more important in predicting the level of heterothermy in 2010 than in $2009(\mathrm{~S} 1)$.

between $\mathrm{T}_{\mathrm{a}}$ and HI was also significant for two birds $(p<0.01)$ and became nonsignificant for only one $(p=0.34)$. Our analysis of the slopes of the relationships between the environmental variables and HI revealed that relationships between $\%$ lunar illumination and HI values were similar between 2009 and $2010(p=0.25)$. Conversely, 

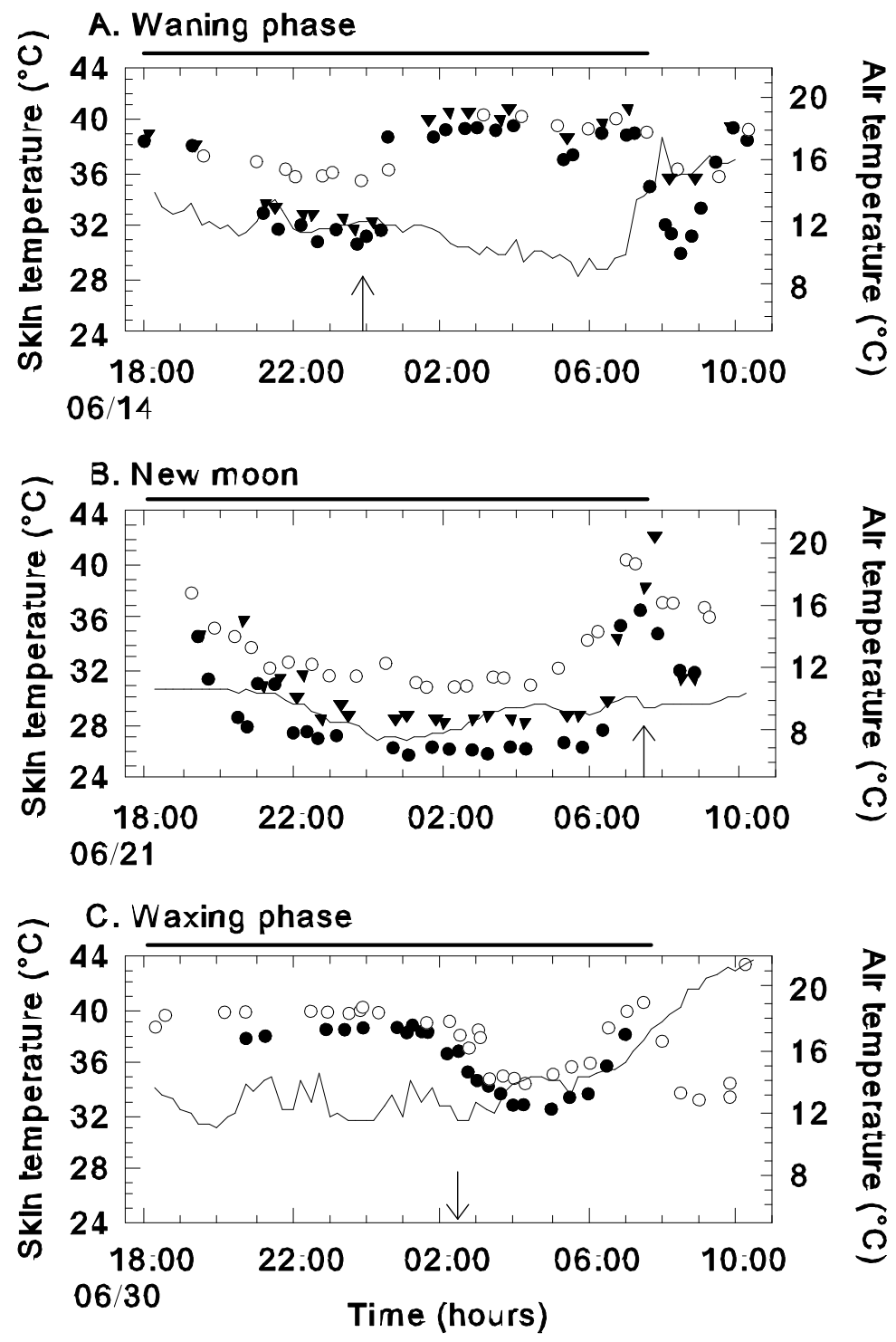

Fig. 5: Decreases and increases in skin temperature $\left(T_{\text {skin }}\right)$ in Freckled Nightjars (different symbols represent individual birds) are synchronized with moonset (downward arrow) and moonrise (upward arrows), respectively. Night-time reductions in $\mathrm{T}_{\text {skin }}$ below $\mathrm{T}_{\text {skin-mod }}$ generally followed shortly after dusk during waning periods (A \& B) or coincided with moonset during the waxing phase $(\mathrm{C})$. Conversely, $\mathrm{T}_{\text {skin }}$ generally increased above $\mathrm{T}_{\text {skin-mod }}$ after moonrise during waning periods (A) or at dawn during waxing periods. In each figure, air temperature is represented by the solid line and the black horizontal bars represent night-time. These examples are from data collected in 2009 but the same patterns occurred in 2010. 
the relationship between $\mathrm{T}_{\mathrm{a}}$ and HI values were different between the years $(p=0.002)$ because of the stronger influence of $\mathrm{T}_{\mathrm{a}}$ on $\mathrm{HI}$ values for two of the three birds during the colder and drier winter of 2010. However, the standardized beta values for lunar illumination were still higher than those for $\mathrm{T}_{\mathrm{a}}$ in the two birds that showed a significant effect of $\mathrm{T}_{\mathrm{a}}$ on heterothermy, suggesting that the effect of lunar illumination was stronger than $\mathrm{T}_{\mathrm{a}}(\mathrm{S} 1)$.

All six nightjars exhibited large increases in $\mathrm{T}_{\text {skin }}$ synchronized with moonrise and large decreases in $\mathrm{T}_{\text {skin }}$ synchronized with moonset. These changes were easily detectable and predictable (Fig. 5), and we found that $\mathrm{T}_{\text {skin }}$ was significantly higher immediately before moonset and after moonrise than immediately after moonset and before moonrise (i.e., $\mathrm{T}_{\text {skin }}$ was higher when the moon was up; $p<0.001$ ). Heterothermic patterns were also occasionally influenced by weather conditions that blocked the moon, but since nights with cloud or rain were rare we could not verify this statistically. For example, during the early mornings of 16 and 17 June 2009, dense fog coincided with moonrise (00h50 and 01h50), completely eliminating lunar illumination. The two nightjars that were successfully radio-tracked on that night rewarmed to $T_{\text {skin-mod }}$ only after the fog dissipated 3-4 hrs after moonrise. On the other hand, a nightjar we were monitoring during the early moonlit morning of 14 July 2010 did not reduce $\mathrm{T}_{\text {skin }}$ at all, despite becoming inactive, when a thick cloud bank covered the site from $03 \mathrm{~h} 00$ until dawn.

\section{DISCUSSION}

Our results reveal that heterothermy in Freckled Nightjars inhabiting a winter-rainfall succulent desert habitat is predicted more strongly by lunar phase than by air temperature. 
Thermoregulatory patterns were tightly coupled with the availability of nocturnal lunar illumination and the birds became increasingly heterothermic during the new moon periods of the lunar cycle when lower light intensity and shorter periods of lunar illumination limited foraging opportunities. We also found that the relative importance of environmental variables varied between years, with $\mathrm{T}_{\mathrm{a}}$ having a stronger influence during 2010 when it was both drier and colder than in 2009. Nevertheless, lunar illumination had a stronger effect on heterothermy than $T_{a}$ in both years. Air temperatures on both new moon nights of 2010 were among the lowest we recorded during the study, and likely explain, in part, the increased importance of $\mathrm{T}_{\mathrm{a}}$ on the level of heterothermy expressed.

Visually-orienting nocturnal predators, including aerial foraging caprimulgids, likely have reduced ability to detect their prey and increased predation risk during periods of near darkness, resulting in reduced foraging opportunities (Ashdown and McKechnie 2008; Jetz et al. 2003; Woods and Brigham 2008). The Freckled Nightjars we studied appeared to increase their reliance on saving energy when foraging opportunities were limited by low light levels, even though aerial insects appeared to be abundant on all nights, irrespective of $\%$ lunar illumination or $\mathrm{T}_{\mathrm{a}}$. The sporadic and unpredictable occurrence of dense fog or rain, which generally lasts two to four days in the succulent Karoo during winter, may impose extended periods of unsuitable foraging conditions for Freckled Nightjars; thus, they may have to undergo extended periods of fasting. Heterothermy during periods of the night with complete darkness may therefore allow birds to conserve the energy necessary to survive unpredictable periods of fasting. Our data support the predictions of Pravosudov and Lucas (2000) that heterothermy should 
increase as foraging opportunities and/or success decrease, particularly if the costs of maintaining homeothermy during the inactive period are high.

Unlike the birds in the present study, Freckled Nightjars (C. t. granosus) from a summer rainfall region (Magaliesberg, South Africa), exhibited no correlation between patterns of heterothermy and lunar cycle (McKechnie et al. 2007). In contrast to wet and relatively productive winters in the Kamiesberg region, winters in the Magaliesberg region are cool and dry with low nocturnal insect availability (Ashdown and McKechnie 2008), suggesting that general scarcity of prey and cold temperatures are the primary proximate factors determining heterothermy use in the Magaliesberg population. The latter study, together with our finding that temperature became a stronger predictor of heterothermy in the drier and colder year, suggests that lunar illumination will be less important in predicting heterothermy in regions where seasonally cold temperatures and aridity (and associated reduced food availability) coincide.

The six birds in our study showed considerable variation in minimum $\mathrm{T}_{\text {skin, }}$, ranging from 10.5 to $28.6^{\circ} \mathrm{C}$ (both males). Similar variation in minimum $\mathrm{T}_{\text {skin }}$ occurred in Freckled Nightjar population from the Magaliesberg (McKechnie et al. 2007), although in the latter study $\mathrm{T}_{\text {skin }}$ was consistently higher in males (generally above $30^{\circ} \mathrm{C}$ ), and only females entered deep torpor. In contrast, variation in minimum $\mathrm{T}_{\text {skin }}$ in our study population did not appear to be related to gender, with males as well as females entering deep torpor. In the eastern parts of southern Africa, Freckled Nightjars generally breed during early summer (September to November), but nothing is known about the species' breeding in western southern Africa (Spottiswoode and Jackson 2005). During our study in early June2010, we found a fledging roosting next to a female, suggesting that there 
was breeding activity during, or at least shortly before, our study period. None of the individuals we monitored showed any evidence of incubation or provisioning young during the study, and therefore we cannot speculate whether individual variation in heterothermy was influenced by breeding cycles.

Globally, there is a latitudinal gradient in the availability of semi-darkness, with (1) longer twilight durations at higher latitudes increasing semi-dark conditions, and (2) moonlight becoming a progressively less important factor determining semi-darkness at higher latitudes where twilight durations are longer and more variable across seasons. Mills (2008) predicted that organisms whose biological rhythms and activity patterns are dependent on semi-darkness will become increasingly dependent on the lunar cycle at lower latitudes where twilight duration is reduced. Similarly, we predict that lunar related heterothermy in endotherms that require semi-darkness for activity should be more important in subtropical and tropical regions where foraging opportunities are reduced when no moon is available. Moreover, we predict that lunar-related heterothermy in these species would be most important in tropical regions, where dusk and dawn durations are shortest, further reducing foraging opportunities.

Circadian and circannual rhythms are commonly found in endothermic heterothermy (Körtner and Geiser 2000) but to the best of our knowledge, no other studies have shown a cyclical pattern in heterothermy with approximately monthly periodicity. Riek, Körtner and Geiser (2010) demonstrated a possible relationship between the lunar cycle and $\mathrm{T}_{\mathrm{b}}$, using a categorical analysis of continuous data to compare mean $\mathrm{T}_{\mathrm{b}}$ values per hour on nights with more than $50 \%$ lunar illumination and those with less than 50\% lunar illumination. They found that eastern tube-nosed bats 
(Nyctimene robinsoni) maintained higher normothermic $\mathrm{T}_{\mathrm{b}}$ around new moon, although the pattern does not appear to be tightly linked to moonrise/moonset within a night. Riek et al.'s (2010) analysis did not specifically account for the influence of $\mathrm{T}_{\mathrm{a}}$ and moon phase in a single model, making it difficult to judge how important the lunar cycle is relative to $T_{a}$ in predicting $T_{b}$.

Although patterns of heterothermy have been investigated in many endotherms, including several species of caprimulgid birds, our data are the first to report a strong link between heterothermy and lunar cycles. In cases where temperature is the most important determinant of heterothermy, the lunar cycle might still mediate the relationship. Our data also highlight the need to quantify heterothermy using a continuous variable; had we analyzed our data using the more commonly used binary approach (i.e., torpor vs. no torpor) using a torpor cut-off $\mathrm{T}_{\text {skin }}$ value, we would have interpreted our data as showing heterothermy only around new moon, since all the variation in above the cut-off $\mathrm{T}_{\text {skin }}$ value would have been discarded.

Although we did not directly test how foraging opportunities mediated by the lunar cycle affect foraging success in Freckled Nightjars, our data strongly suggest that foraging opportunities are important factors determining heterothermy in endotherms, even when food is abundant (Schubert et al. 2009). The subtle, but important distinction between heterothermy cued by limited foraging opportunities rather than reduced food abundance, reiterates that factors other than absolute food abundance should also be considered in studies on endothermic heterothermy. The patterns of heterothermy we recorded in Freckled Nightjars in this study are novel among heterotherms studied to date and highlight the need for more studies of thermoregulation on sub-tropical and tropical 
organisms. Our data also provide further evidence that heterothermy in endotherms is a flexible response, whose expression varies with ecological conditions to balance the various costs and benefits of thermoregulation.

\section{ACKNOWLEDGEMENTS}

We are particularly grateful to P. and V. Benadie from Noheep Farm for their unending hospitality, N. Hannekom for access to his property, and the late N. Beukes for providing

us with valuable information about these nightjars. E. Templeton, R. Bruyns, S.Leijenaar, S. Hoffmann, C. Purchase, A. Russell, J. Humphreys and C. Vos provided valuable assistance in collecting data. This study was facilitated by funding from the University of Pretoria, Natural Sciences and Engineering Research Council - Canada, and DST/NRF Centre of Excellence at the Percy FitzPatrick Institute. All experimental procedures were approved by the University of Pretoria's Animal Use and Care Committee (clearance \#ECO10-09).

\section{REFERENCES}

Angilletta MJ, Jr., Cooper BS, Schuler M and Boyles JG (2010) The evolution of thermal physiology in endotherms. Front Biosci E2:861-881.

Arnold W, Ruf T, Reimoser S, Tataruch F, Onderscheka K and Schober F (2004) Noctural hypometabolism as an overwintering strategy of red deer (Cervus elaphus). Am J Physiol Regul Integr Comp Physiol 286:R174-R181.

Ashdown RAM and McKechnie AE (2008) Environmental correlates of Freckled Nightjar activity in a seasonal, subtropical habitat. J Ornithol 149:615-619. 
Bieber C and Ruf T (2009) Summer dormancy in edible dormice (Glis glis) without energetic constraints. Naturwissenschaften 96:165-171.

Boyles JG, Smit B and McKechnie AE (2011) A new comparative metric for estimating heterothermy in endotherms. Physiol Biochem Zool 84:115-123.

Bozinovic F, Munoz JLP, Naya DE and Cruz-Neto AP (2007) Adjusting energy expenditures to energy supply: food availability regulates torpor use and organ size in the Chilean mouse-opossum Thylamys elegans. Journal of Comparative Physiology B-Biochemical Systemic and Environmental Physiology 177:393-400.

Brigham RM and Barclay RMR (1992) Lunar influence on foraging and nesting activity of Common Poorwills (Phalaenoptilus nuttallii). Auk 109:315-320.

Brigham RM, Gutsell RCA, Wiacek RS and Geiser F (1999) Foraging behavior in relation to the lunar cycle by Australian Owlet-nightjars (Aegotheles cristatus). . Ети 99:253-261.

Brigham RM, Körtner G, Maddocks TA and Geiser F (2000) Seasonal use of torpor by free-ranging Australian owlet-nightjars (Aegotheles cristatus). Physiol Biochem Zool 73:613-620.

Grigg GC, Beard LA and Augee ML (2004) The evolution of endothermy and its diversity in mammals and birds. Physiol Biochem Zool 77:982-997.

Horning M and Trillmich F (1999) Lunar cycles in diel prey migrations exert a stronger effect on the diving of juveniles than adult Galapagos fur seals. Proc R Soc Biol Sci Ser B 266:1127-1132.

Huey RB and Slatkin M (1976) Cost and benefits of lizard thermoregulation. Q Rev Biol 51:363-384. 
Humphries MM, Thomas DH and Kramer DL (2003) The role of energy availability in mammalian hibernation: a cost-benefit approach. Physiol Biochem Zool 76:165179.

Jetz W, Steffen J and Linsenmair KE (2003) Effects of light and prey availability on nocturnal, lunar and seasonal activity of tropical nightjars. Oikos 103:627-639.

Körtner G and Geiser F (2000) The temporal organization of daily torpor and hibernation: circadian and circannual rhythms. Chronobiol Int 17:103-128.

McKechnie AE, Ashdown RAM, Christian MB and Brigham RM (2007) Torpor in an Afrotropical caprimulgid, the Freckled Nightjar (Caprimulgus tristigma). J Avian Biol 38:261-266.

Mills AM (2008) Latitudinal gradients of biologically useful semi-darkness. Ecography $31: 578-582$.

Mucina L, Jürgens N, le Roux A, Rutherford MC, Schmiedal U, Esler KJ, Powrie LW, Desmet PG and Milton SJ (2006) Succulent Karoo Biome. In The Vegetation of South Africa, Lesotho and Swaziland, L Mucina and MC Rutherford, eds, South African National Biodiversity Institute, Pretoria.

Mzilikazi N and Lovegrove BG (2004) Daily torpor in free-ranging rock elephant shrews, Elephantulus myurus: A year-long study. Physiol Biochem Zool 77:285-296.

Mzilikazi N, Lovegrove BG and Ribble DO (2002) Exogenous passive heating during torpor arousal in free-ranging rock elephant shrews, Elephantulus myurus. Oecologia 133:307-314. 
Pravosudov VV and Lucas JR (2000) The costs of being cool: a dynamic model of nocturnal hypothermia by small food-caching birds in winter. J Avian Biol 31:463-472.

Riek A, Körtner G and Geiser F (2010) Thermobiology, energetics and activity patterns of the eastern tube-nosed bat (Nyctimene robinsoni) in the Australian tropics: effect of temperature and lunar cycle. J Exp Biol 213:2557-2564.

Schubert KA, Boerema AS, Vaanholt LM, de Boer SF, Strijkstra AM and Daan S (2009) Daily torpor in mice: high foraging costs trigger energy-saving hypothermia. Biol Lett 6:132-135.

Smit B and McKechnie AE (2010) Do owls use torpor? Winter thermoregulation in freeranging Pearl-Spotted Owlets and African Scops-Owls. Physiol Biochem Zool $83: 149-156$.

Spottiswoode CN and Jackson HD (2005) Freckled Nightjar. In Roberts birds of southern Africa, PAR Hockey, WRJ Dean and PG Ryan, eds, John Voelcker Bird Book Fund, Cape Town.

Stawski C and Geiser F (2010) Fat and fed: frequent use of summer torpor in a subtropical bat. Naturwissenschaften 97:29-35.

Warnecke L, Turner JM and Geiser F (2008) Torpor and basking in a small arid zone marsupial. Naturwissenschaften 95:73-78.

Woods CP and Brigham RM (2008) Common poorwill activity and calling behavior in relation to moonlight and predation. Wilson J Ornithol 120:505-512. 
Supplementary online material:

S1. Linear correlation coefficients and multiple regression partial correlation coefficients, model fit and significance of Heterothermy Index as a function of percentage Lunar Illumination and Air Temperature in six Freckled Nightjars in the Kamiesberg, South Africa. Significance $(p<0.05)$ indicated in bold print.

\begin{tabular}{ccccccccc}
\hline & \multicolumn{3}{c}{$\%$ Lunar illumination } & & \multicolumn{3}{c}{ Air Temperature } \\
\cline { 2 - 3 } \cline { 7 - 8 } & Beta & $\mathrm{R}^{2}$ & $P$ & & Beta & $\mathrm{R}^{2}$ & $P$ \\
\hline Linear regression & & & & & & & \\
2009 Female \#242 & -0.95 & 0.90 & $\mathbf{0 . 0 0 0}$ & & -0.51 & 0.26 & 0.021 \\
2009 Female \#119 & -0.96 & 0.93 & $\mathbf{0 . 0 0 0}$ & & -0.36 & 0.13 & 0.336 \\
2009 Male \#104 & -0.84 & 0.71 & $\mathbf{0 . 0 0 0}$ & & -0.46 & 0.21 & $\mathbf{0 . 0 3 6}$ \\
2011 Male \#841 & -0.81 & 0.66 & $\mathbf{0 . 0 0 2}$ & & -0.65 & 0.42 & $\mathbf{0 . 0 3 1}$ \\
2011 Male \#721 & -0.71 & 0.50 & $\mathbf{0 . 0 0 0}$ & & -0.62 & 0.39 & $\mathbf{0 . 0 0 0}$ \\
2011 Male \#941 & -0.91 & 0.82 & $\mathbf{0 . 0 0 0}$ & & -0.88 & 0.77 & $\mathbf{0 . 0 0 0}$ \\
& & & & & & & \\
Multiple regression & & & & & & & \\
2009 Female \#242 & -0.89 & & $\mathbf{0 . 0 0 0}$ & & -0.13 & & 0.117 \\
2009 Female \#119 & -0.93 & & $\mathbf{0 . 0 0 0}$ & & -0.19 & & 0.057 \\
2009 Male \#104 & -0.79 & & $\mathbf{0 . 0 0 0}$ & & -0.12 & & 0.382 \\
2011 Male \#841 & -0.67 & & $\mathbf{0 . 0 2 6}$ & & -0.24 & & 0.345 \\
2011 Male \#721 & -0.53 & & $\mathbf{0 . 0 0 0}$ & & -0.36 & & $\mathbf{0 . 0 0 7}$ \\
2011 Male \#941 & -0.58 & & $\mathbf{0 . 0 0 0}$ & & -0.49 & & $\mathbf{0 . 0 0 1}$ \\
& & & & & & & \\
\hline
\end{tabular}

